Article

\title{
In-Situ Deposition of Plasmonic Gold Nanotriangles and Nanoprisms onto Layered Hydroxides for Full-Range Photocatalytic Response towards the Selective Reduction of p-Nitrophenol
}

\author{
Javier Graus ${ }^{1}$, Carlos J. Bueno-Alejo ${ }^{1, *}$ and Jose L. Hueso ${ }^{1,2, *}$ \\ 1 Institute of Nanoscience of Aragon (INA) and Department of Chemical and Environmental Engineering, \\ University of Zaragoza, Campus Rio Ebro, I+D+i Building, 50018 Zaragoza, Spain; ggraus@gmail.com \\ 2 Networking Research Center on Bioengineering, Biomaterials and Nanomedicine (CIBER-BBN), \\ 28029 Madrid, Spain \\ * Correspondence: carlosb@unizar.es (C.J.B.-A.); jlhueso@unizar.es (J.L.H.); Tel.: +34-876-555-611 (C.J.B.-A.); \\ +34-876-555-442 (J.L.H.)
}

Received: 25 July 2018; Accepted: 24 August 2018; Published: 27 August 2018

check for updates

\begin{abstract}
In this work, we present photocatalysis as a greener alternative to conventional catalysis where harsh reaction conditions, temperature and/or pressure are needed. Photodegradation of organic pollutants is a cost-effective, eco-friendly solution for the decontamination of water and air, and is a field that has been continuously growing over the last decade. Plasmonic metal nanoparticles absorb light irradiation that is transferred to the chemical reaction in a different fashion. Furthermore, plasmonic nanostructures can be combined with other materials, such as semiconductors or a basic support, to create hybrid systems capable of overcoming certain challenges that photocatalysis is facing nowadays and to expand the photocatalytic response towards the whole visible-near infrared (Vis-NIR) ranges. The main objective of this work has been to in-situ synthesize plasmonic anisotropic gold nanoparticles onto hydrotalcite (HT) and calcined hydrotalcite (CHT) supports by way of a sequential deposition-reduction (DR) process and to evaluate their efficiency as heterogeneous catalysts towards the selective oxidation of p-nitrophenol (hereafter 4-NP), a well-known model contaminant, either in the absence or the presence of full-range light irradiation sources (LEDs) spanning the whole UV-Vis-NIR range. Special attention has been paid to the optimization of the catalyst preparation parameters, including the $\mathrm{pH}$ and the concentration of reducing and stabilizing agents. Interestingly, the use of thermally modified hydrotalcites has enabled a strong metal-support interaction to induce the preferential formation of triangular-shaped Au nanoparticles with ca. $0.8 \mathrm{wt} . \%$ loading while increasing the colloidal stability and surface area of the catalyst with respect to the commercial untreated HT supports.
\end{abstract}

Keywords: gold nanotriangles; plasmonic photocatalyst; full-range; selective reduction; hydrotalcite; magnesium oxide; LED; nitrophenol

\section{Introduction}

Chemical and petrochemical industries produce an extensive range of harmful and highly toxic organic contaminants such as phenols or $\mathrm{CO}_{x}[1,2]$. So far, the removal strategy has been to develop catalysts that promote or activate chemical reactions that often require the use of toxic and aggressive chemical oxidants, chromates and permanganates among them, generating toxic by-products as a result of the pollutant decomposition process [3]. The interest of the scientific community is shifting towards the development of greener alternatives [4]. Photocatalysis is a promising technology that 
obtains the energy required to activate the pollutant degradation from solar [5] or artificial light [6] and take advantage of semiconductors materials and metal nanoparticles to trigger different mechanisms that promote the degradation. Since the catalytic properties of metal nanoparticles are usually size and shape-dependent [5], the ability to control sizes and morphologies of the nanoparticles has become an important research area in nanomaterials science. Although the number of potential possibilities with nanomaterials is endless, nanostructured hybrid catalyst, plasmonic metal nanoparticles and quantum dots stands out as three of the most promising nanostructures for many important applications $[7,8]$.

Gold-based metallic nanoparticles turn catalytically active in numerous reactions when they are well dispersed on metal oxides. Although research of gold catalysts has been mainly focused on the influence of the size of Au particles, they also exhibit other appealing optical characteristics such as plasmonic properties. In this regard, Au has prompted tremendous research interest in the past decade because of its surface plasmon resonance. Localized surface plasmonic resonance (LSPR) is a specific phenomenon that specially applies to metallic nanostructures whose "cloud" of electrons located at the surface oscillates with maximum amplitude when is excited by light of a specific matching wavelength. The LSPR can be tuned by tailoring some parameters of the nanoparticles, such as size, shape, distance between plasmonic particles and the nature of the surrounding medium. As a general rule, bigger nanoparticles as well as more complex morphologies lead to longer red shifted absorptions in the LSPR. In fact, there are currently great research efforts on the photocatalytic field to shift the absorption capabilities and span the photo-response of catalysts towards the visible-NIR range, thereby maximizing the use of natural sunlight as a green and clean energy source [9-11].

Hydrotalcite compounds, or layered double hydroxides (LDHs), are a special group of materials among anionic clays the structure of which is based on brucite layers $\mathrm{Mg}(\mathrm{OH})_{2}$ [12] where trivalent cations have replaced some divalent cations. The positive charge generated for the trivalent cations in the structure is compensated by interlayer anions placed between the brucite-like layers. This type of materials has been widely used in heterogeneous catalysis as a basic support for other materials like gold, silver and so forth ... [13-16], or acting as the sole catalyst of the reaction [17-19]. Xiao et al. [15] supported Au nanoparticles on HT and modified the structure of the catalyst with several metals in order to change the selectivity of the nitro-aromatic compounds reduction reaction. Furthermore, Santos Arcanjos and co-workers have recently synthesized a hybrid catalyst with $\mathrm{TiO}_{2}$ on $\mathrm{HT}$ and doped with iron oxide for the treatment of waste water from mills. The authors not only achieved excellent removal rates of pollutants but also a good recyclability of the catalyst due to the magnetic properties provided by the iron oxide doping species [14].

Heterogeneous catalytic degradation of organic pollutants is an effective strategy for water treatment $[20,21]$. Metal supported catalysts favour the heterogeneous catalysis in several ways. Due to their small size the nanoparticles enhance the adsorption of molecules compared to bulk metals as they have a much greater surface to volume ratio. The reactivity of the species adsorbed is also enhanced since metal nanoparticles possess a high Fermi energy level to diminish the reduction potential of the reaction. Thus, metal nanoparticles can work as active catalysts for many redox reactions and have become an important field of research in catalysis. Even though catalytic metal nanoparticles have brought new possibilities to the field of catalysis some disadvantages associated to regular catalysis remain opened. The main reason strives on the fact that the energy demanded to activate the catalytic reaction is usually provided by temperature and/or pressure.

Photocatalysis is a greener approach within the catalysis field, which stands up for the use of light, like solar energy, as the energetic vector driving the chemical reaction. Photodegradation of organic contaminants by photocatalysts is a cost-effective, eco-friendly and effective solution for water and air decontamination. Plasmonic nanoparticles under light irradiation can trigger different powerful mechanisms for the oxidation or reduction of pollutants. The photocatalytic reactions are highly dependent on the catalyst's light absorption properties, surface area, energy band level and the charge separation behaviour of the photocatalyst. The beneficial plasmonic effect on photocatalysts has been well proven [22]. Under plasmonic excitation, the elevated electromagnetic field increases 
the generation rate of energetic charge carriers, resulting in a higher probability of charge-transfer involved (i.e., redox) reactions [17]. Remarkable efforts have been made to enhance the efficiency and stability of the catalyst in order to reach higher efficiency. Such efforts have been directed towards better morphology control of nanoparticles, separation of generated charge carriers and innovative hybrid structures [23].

4-Nitrophenol (4-NP) is a chemical pollutant present in industrial effluents and agricultural wastewaters [24,25]. There are different strategies devoted to 4-NP removal from water [26]. Among them, the selective reduction to 4-NP is one the simplest and more efficient methods and a way to reduce costs in industry since 4-Aminophenol (4-AP) has different applications in pharmacological industry, for instance for the preparation of paracetamol and acetanilide [27]. However, it is kinetically restricted in the absence of a catalyst [28]. In addition to its industrial importance, the 4-NP reduction to 4-AP in the presence of a large excess of $\mathrm{NaBH}_{4}$ has become one of the most used models for the study of the catalytic activity of gold nanoparticles so we chose that reaction to test our synthesized materials in the presence of different LEDs irradiating at different wavelengths $[27,29,30]$. The main objective of this work has been three-fold: (i) to develop a novel synthesis strategy to generate gold-based nanostructures with anisotropic shapes, including triangular nanoplates or nanoprisms in situ decorated onto commercial hydrotalcite supports; (ii) improve the stability of the catalysts on thermally modified hydrotalcite supports; and (iii) to evaluate their role as full-spectrum plasmonic photocatalysts towards the selective reduction of nitrophenols upon irradiation of different light emitting diodes (LEDs) in the UV-vis-NIR ranges.

\section{Results and Discussion}

\subsection{Evaluation of the Synthesis Parameters for the In-Situ Generation and Deposition of Gold-Based} Anisotropic Nanoparticles onto Hydrotalcite Supports

It has been previously demonstrated that basic environments using $\mathrm{NaOH}$ may favour the formation of triangular-shaped gold nanostructures (hereafter GNT) in aqueous solution [31]. Therefore, hydrotalcite (Figure 1a) was selected in first place to explore the critical role of $\mathrm{pH}$ as an influencing parameter due to its stability under alkaline conditions [32]. The synthesis of gold nanoparticles has been thoroughly addressed in the materials and methods section and included the use of increasing concentrations of $\mathrm{NaOH} 0.5 \mathrm{M}$ to adjust the $\mathrm{pH}$ of the initial suspensions from 10 to 13 while keeping a fixed ratio of sodium borohydride at $2.1 \mathrm{mM}$ as reducing agent. In a second set of experiments, the molar ratio of reducing agent was systematically increased (see Experimental Section for further details). All the resulting suspensions were monitored by UV-Vis spectroscopy (Figure $1 \mathrm{~b}, \mathrm{c}$ ) and transmission electron microscopy (TEM) analysis. Figure $1 \mathrm{~d}-\mathrm{g}$ show that the $\mathrm{pH}$ variation plays a critical role to induce the formation of Au anisotropic nanoparticles on HT. A clear difference in the final shape of the Au NPs was observed at higher $\mathrm{pH}$ values (Figure 1d,e). In this latter scenario, an increasing presence of triangular-shaped nanostructures was clearly observed by TEM analysis (sample will be named hereafter as Au-HT (T). In contrast, when the $\mathrm{pH}$ was adjusted to $\mathrm{pH}$ values slightly higher than the ones naturally obtained in the presence of the $\mathrm{HT}$, a major presence of spherical Au NPs was detected (Figure 1f,g and sample named as Au-HT (M)).

Increasing the $\mathrm{pH}$ from 10 to 13 also led to a progressive red-shift of the SPR maximum (Figure 1b,c). The samples in which Au nanospheres were preferentially formed exhibited a peak near to the typical $530 \mathrm{~nm}$ SPR reported for small Au nanoparticles with sizes above $2 \mathrm{~nm}$ (Figure 1c) [33]. However, a red shift of the Au SPR could be observed due to the formation of anisotropic Au nanoparticles $(10.8 \pm 2.9 \mathrm{~nm})$ (mostly planar gold nanotriangles) in the HT surface as shown in the TEM images displayed in Figure 1b). Even though SPR for larger triangular gold nanoprisms (GNT) have been extensively reported to be in near infrared (NIR) range [31], the small size of the synthetized nanoparticles yielded an absorption band close to $550 \mathrm{~nm}$ (see Figure 1b). Anisotropic gold nanoparticles groups divided into triangles, spheres and rhombohedral particles (the latter in a 
lower extent) were identified at different $\mathrm{pH}$ conditions, being the optimal $\mathrm{pH}=12.5$ to render the maximum proportion of GNTs.
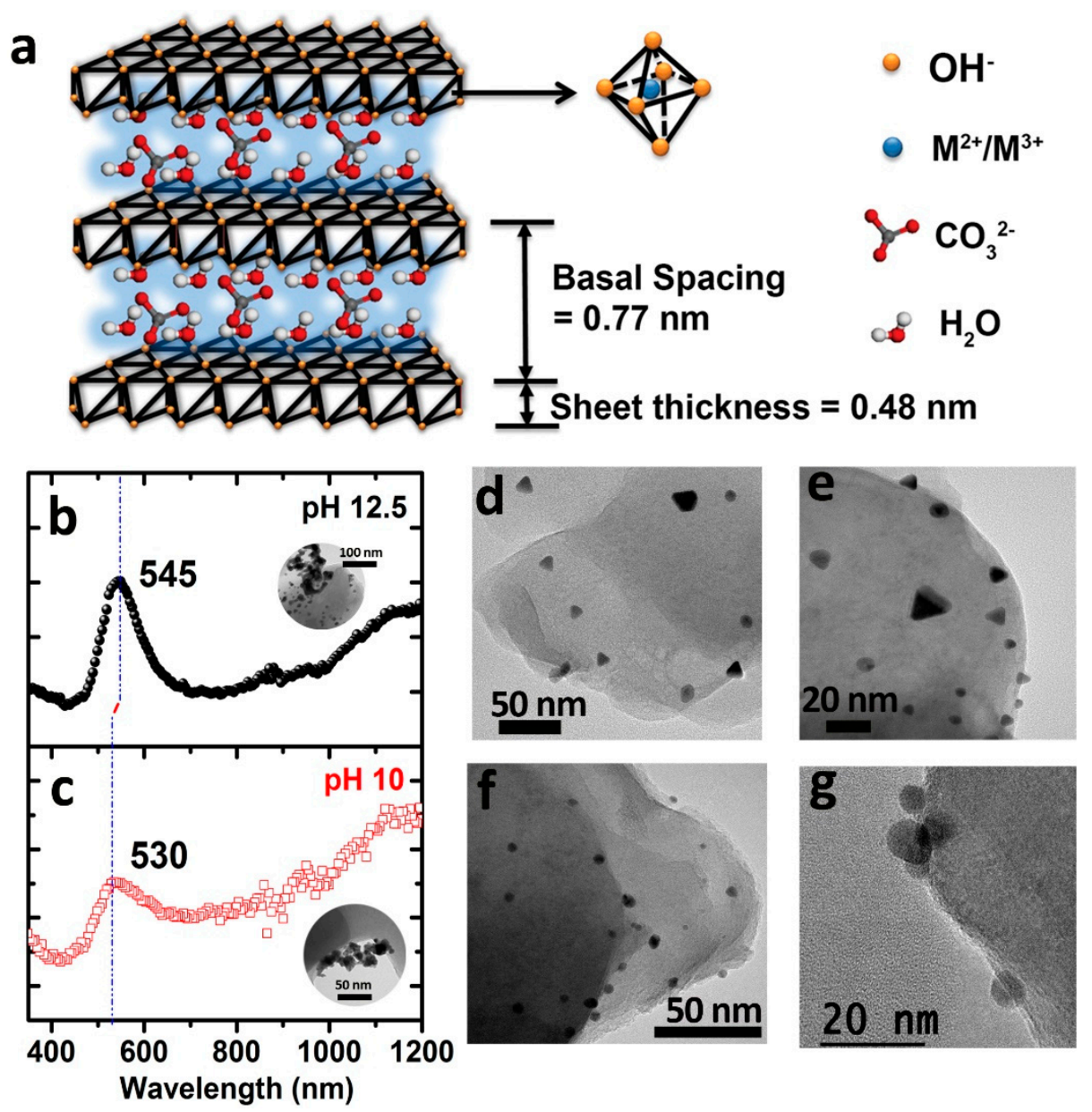

Figure 1. Evaluation of the $\mathrm{pH}$ conditions on the synthesis of gold decorated hydrotalcites: (a) Scheme depicting the structure of the hydrotalcite selected as anionic clay support with a well-known stability under alkaline conditions. The layered double hydroxide is based on brucite layers $\mathrm{Mg}(\mathrm{OH})_{2}$ alternated with $\mathrm{Al}^{3+}$ cations [9] that have replaced some divalent sites. The positive charge generated for the trivalent cations in the structure is compensated by interlayer anions placed between the brucite-like layers; (b) UV-Vis spectrum corresponding to the Au/HT (T) sample synthesized at $\mathrm{pH}=12.5$ (inset: transmission electron microscopy (TEM) image of gold aggregates contributing to the enhanced absorbance at higher wavelengths); (c) UV-Vis spectrum corresponding to the Au/HT (M) sample synthesized at $\mathrm{pH}=10$ (inset: TEM image displaying some of the gold aggregates contributing to the scattering observed at higher wavelengths in the UV-Vis spectrum); (d,e) Representative TEM images of the $\mathrm{Au} / \mathrm{HT}(\mathrm{T})$ sample with a preferential formation of triangular-shaped Au NPs; (f,g) Representative TEM images of the Au/HT (M) sample with a major presence of pseudo-spherical Au NPs.

The effect of the $\mathrm{NaBH}_{4}$ concentration in the formation of anisotropic nanoparticles was also systematically evaluated after fixing the $\mathrm{pH}$ at 12.5 as the most suitable alkaline conditions to promote the preferential formation of GNTs. We found that upon adding a 1:1.8 ratio $\mathrm{HAuCl}_{4}: \mathrm{NaBH}_{4}$ (see Figure 2 and also the Experimental section for further details) the proportion of GNTs reached a maximum yield that decreased above and below such concentration of reductant. In this latter series, SPR maxima were restricted within the 550-560 nm wavelengths (Figure 2a-c) with additional absorbance in the NIR region mainly attributable to the scattering of bigger aggregates (see insets in Figure $2 \mathrm{a}-\mathrm{c})$. TEM analysis confirmed that the lower concentration of reducing agent $(2.1 \mathrm{mM})$ 
rendered the major fraction of triangular-shaped gold NPs with average lengths $\times$ widths of $((11.5 \pm 3.9) \times(4.7 \pm 2.0)) \mathrm{nm}$ (Figure $2 \mathrm{~d}$,e). In contrast, the use of higher concentrations of $\mathrm{NaBH}_{4}$ during the synthesis progressively led to the formation of more planar structures of bigger dimensions (Figure 2f,g) and/or the appearance of more pseudo-spherical NPs (Figure 2h,i). In addition, the presence of randomly distributed bigger aggregates became more relevant in the latter conditions (see Figure 2c) thereby suggesting the lack of shape control in a fraction of the gold NPs in situ deposited with the higher concentrations of reducing agent. ICP analyses confirmed that the gold loading was closed to $0.8 \mathrm{wt} . \%$ in all cases (72\% reaction yield).

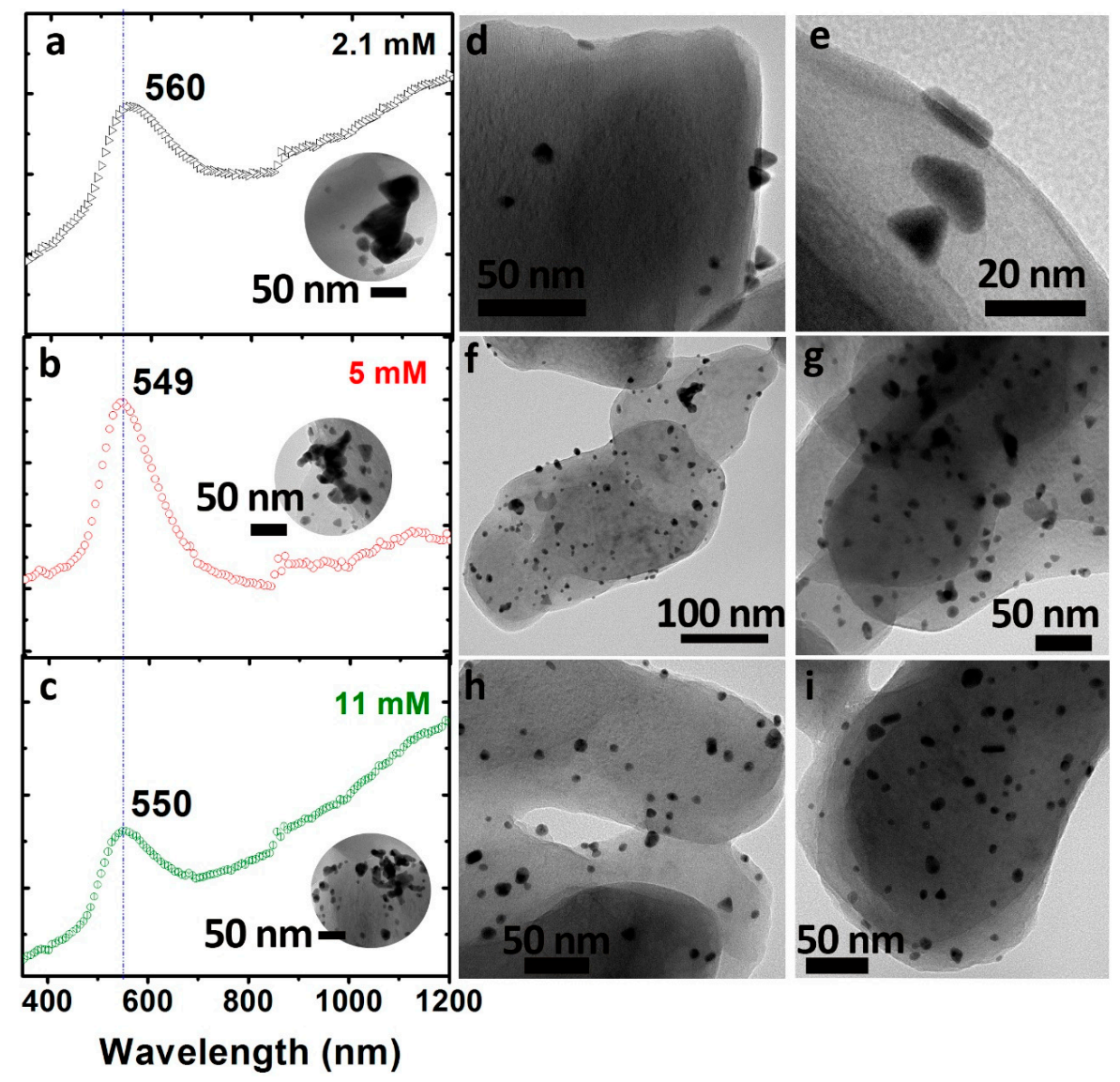

Figure 2. Evaluation of the influence of varying the concentration of reducing agent during the synthesis of Au-HT (T) catalysts at a fixed pH value of 12.5: (a) UV-Vis spectrum of the Au-HT (T) synthesized with $2.1 \mathrm{mM}$ of $\mathrm{NaBH}_{4}$ (inset: representative aggregates formed during the synthesis); (b) UV-Vis spectrum of the Au-HT (T) synthesized with $5 \mathrm{mM}$ of $\mathrm{NaBH}_{4}$ (inset: representative aggregates formed

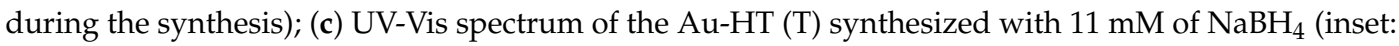
representative aggregates formed during the synthesis); (d,e) Representative TEM images of the Au-HT $(\mathrm{T})$ at $2.1 \mathrm{mM}$ accounting for the preferential formation of triangles/pyramids; $(\mathbf{f}, \mathbf{g})$ Representative TEM images of the Au-HT (T) at $5 \mathrm{mM}$ accounting for lower presence of triangles accompanied by a major fraction of planar-like structures of bigger dimensions; $(\mathbf{h}, \mathbf{i})$ Representative TEM images of the $\mathrm{Au}-\mathrm{HT}(\mathrm{T})$ at $11 \mathrm{mM}$ accounting for the preferential formation of round-shaped Au NPs.

The preliminary catalytic tests with the Au-HT (T) selected sample towards the selective reduction of 4-nitrophenol (4-NP) into 4-aminophenol (4-AP) were not reliable and were accompanied by a wide margin of error (see Figure S1a). We attributed this lack of reproducibility to the poor colloidal stability of the HT in the aqueous media (see Figure S1b). Therefore, additional modifications were required in order to take advantage of these novel catalysts (vide infra). 


\subsection{Gold Catalysts onto Thermally Treated Hydrotalcite Supports}

In order to modify the HT support, we were inspired by the theoretical study carried out by Molina and Hammer [34] that explained the growth of $\mathrm{Au}$ onto $\mathrm{MgO}$ surfaces preferentially forming 3D planar assemblies. Likewise, previous works in the literature [35] reporting that thermal treatments of HT may induce $\mathrm{Al}$ migration into inner layers of the structure to form a stable $\mathrm{Mg}(\mathrm{Al}) \mathrm{O}$ mixed oxide enriched with $\mathrm{MgO}$ in the external layers were also taken into consideration. The commercial unmodified HT supports were subjected to moderate thermal treatments (see Experimental Section for further details). X-ray diffraction (XRD) analysis displayed in Figure 3 showed the main differences between the original HT and the calcined (CHT) supports. Commercial unmodified HT and Au/HT samples showed diffraction peaks at 7.59(d003), 3.84(d006), 5.28(d009), (d015), (d018), (d110), (d113), (d116), similar to those previously reported in the literature [32]. The diffraction at 7.59 degrees correlates with the distance between layers. The intensity of the signal indicates the crystallinity grade of the HT. If a hexagonal structure is assumed, the unit cell parameters $a$ and $c$ are obtained by Bragg's law (Table 1), where $c$ is three times the interlayer distance (003) and $a$ the average distance between the cations in the interlayer [17].

Table 1. Summary of key information retrieved from X-ray diffraction (XRD) and Brunauer-Emmett-Teller (BET) analysis of different samples.

\begin{tabular}{cccccc}
\hline Sample & $\mathbf{a}(\AA)$ & $\mathbf{c}(\AA)$ & Basal Spacing, $(\AA)$ & BET Surface Area $\left(\mathbf{m}^{2} / \mathbf{g}\right)$ & Pore Specific Volume, $\mathbf{V p}\left(\mathbf{c m}^{3} / \mathbf{g}\right)$ \\
\hline $\mathrm{HT}$ & 7.65 & 1.53 & 22.95 & $11.9 \pm 0.1$ & 0.029 \\
$\mathrm{Au} / \mathrm{HT}$ & 7.66 & 1.53 & 22.98 & $11.3 \pm 0.1$ & 0.027 \\
$\mathrm{CHT}$ & - & - & - & $244.4 \pm 2.2$ & 0.19 \\
$\mathrm{Au} / \mathrm{CHT}$ & 7.67 & - & 23.01 & $151.1 \pm 0.4$ & 0.21 \\
\hline
\end{tabular}

XRD analysis of Au/HT samples indicated that the deposition-reduction (DR) method to in situ deploy the gold NPs did not affect the crystalline structure of the support (Figure 3a,b). In contrast, the XRD data of thermally treated support (CHT) corroborated the effective collapse of the HT structure turning into a mixed oxide phase, which holds a MgO-like structure [36], with diffraction peaks at $2 \theta$ $35^{\circ}(111), 42^{\circ}(200)$ and $63^{\circ}(220)$ (Figure $\left.3 a-c\right)$. The resultant material exhibited a higher surface area of $244 \mathrm{~m}^{2} / \mathrm{g}$ (Table 1) upon losing the interlayer with water molecules, the hydroxyl and carbonate groups which evolved to $\mathrm{H}_{2} \mathrm{O}$ and $\mathrm{CO}_{2}$ above $200{ }^{\circ} \mathrm{C}$. Interestingly, the $\mathrm{MgO}$-like structure was able to partially recover its layered assembly, turning into a hydrotalcite-like phase again, when hydrated at basic $\mathrm{pH}$ as evidenced by the XRD (Figure $3 \mathrm{a}-\mathrm{d}$ ). The regeneration of the hydrotalcite structure has been endorsed to the presence of water molecules and hydroxyl groups present in the basic water media compensating the metal-positive charged layers.

This hypothesis was further sustained by XRD (Figure 3) and FTIR analysis of the samples (see Figure S2). that confirmed the partial rehydration of the CHT supports after resuspension in alkaline water and the presence of a broad $\mathrm{OH}$ band at $3420 \mathrm{~cm}^{-1}$ (Figure S2c) non-previously detected in the solid CHT prior to rehydration (Figure S2b). This broad band is attributable to the $\mathrm{O}-\mathrm{H}$ stretching vibration of the metal hydroxide layer water molecules intercalated within the sheets. These results could be explained on the basis of the memory effect previously described for calcined hydrotalcites [37]. Following this memory effect, HT rehydrates and recovers its sheet-like structure back again in the presence of water. Even though in the absence of anions, which could be balancing the positive charge of the sheets, the structure was not as crystalline as the original counterpart prior to the thermal treatment. FTIR analysis further confirmed the transformation of the hydrotalcite phase into a high surface area $\mathrm{Mg}(\mathrm{Al}) \mathrm{O}$ mixed oxide during the thermal treatment at $550{ }^{\circ} \mathrm{C}$ (see $\mathrm{BET}$ values in Table 1). The removal of $\mathrm{CO}_{2}$ during the decomposition led to the formation of substantial porosity within the CHT structure. A shoulder close to $3200 \mathrm{~cm}^{-1}$ is attributed to the interaction between the $\mathrm{CO}_{3}{ }^{2-}-\mathrm{H}_{2} \mathrm{O}$ molecules present in the interlayer region [12]. The bending vibration of the water in the interlayer is also appreciated in the broad bands at $1637 \mathrm{~cm}^{-1}$ (Figure S2). The strong absorption 
peak at $1359 \mathrm{~cm}^{-1}$ can be assigned to the vibration of $\mathrm{CO}_{3}{ }^{2-}$. The band characteristic of metal-oxygen bond M-O stretching appears near $700 \mathrm{~cm}^{-1}$. The sharp peaks in the $500-700 \mathrm{~cm}^{-1}$ range are produced by several lattice vibrations associated to metal hydroxide layers [12]. Therefore, FTIR confirmed the effective elimination of the interlayer water and carboxyl groups and the surface hydroxyl groups. It also corroborated the partial reconstruction of the $\mathrm{CHT}$ structure after rehydration in basic aqueous media (Figure S2).

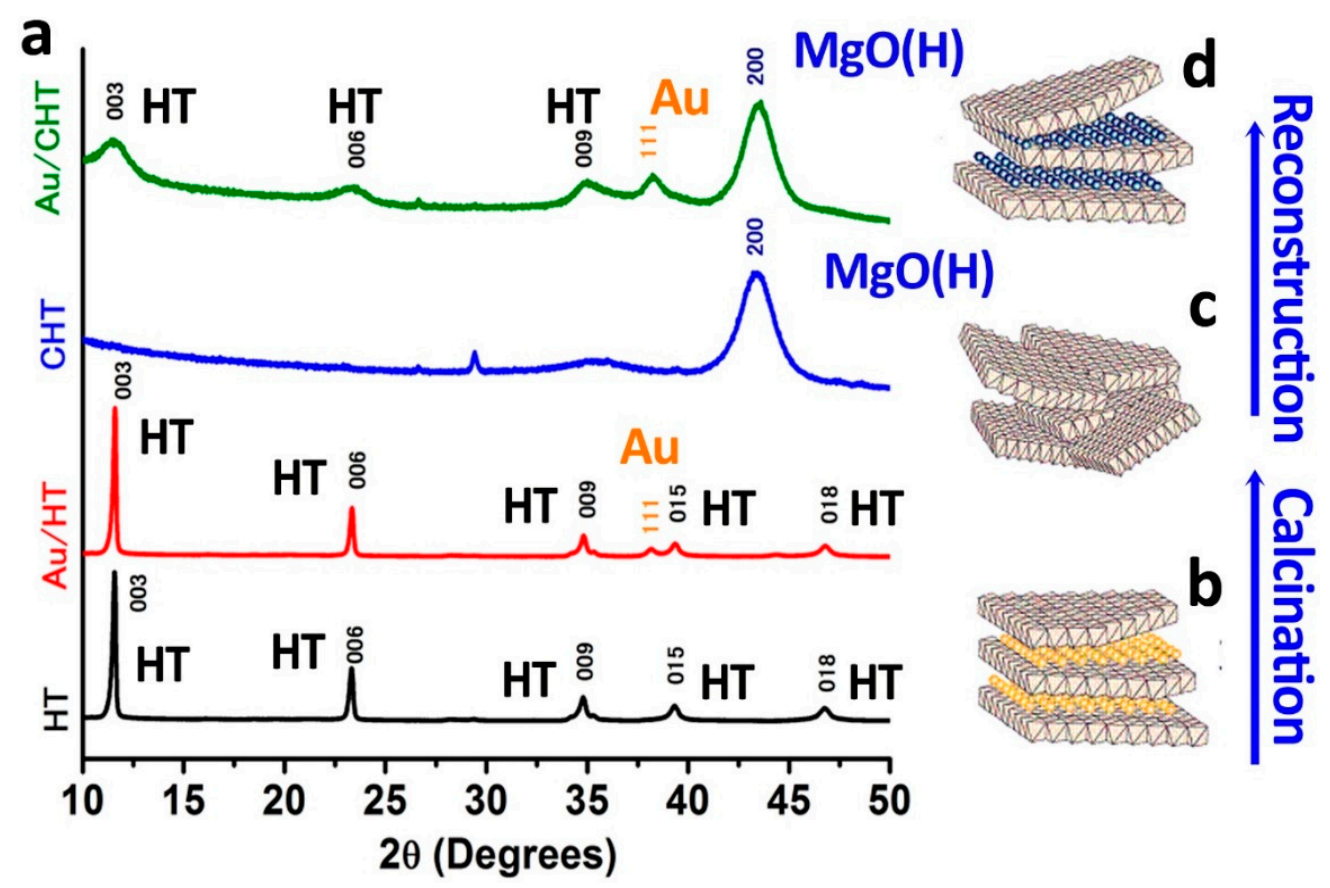

Figure 3. (a) XRD patterns of original and gold decorated samples before (HT and Au/HT samples) and after calcination in air at $550{ }^{\circ} \mathrm{C}$ for $5 \mathrm{~h}$ (CHT and Au/CHT samples); (b) Schematic layered structure of HT before calcination with an interlayer containing water molecules, hydroxyl and carboxyl anions (orange); (c) Scheme of the HT after calcination (CHT) where the layered structure collapses into a $\mathrm{Mg}(\mathrm{Al}) \mathrm{O}$ phase; (d) Scheme of the rehydrated $\mathrm{CHT}$ after resuspension in basic water where the blue circles represent the presence of water and $\mathrm{OH}^{-}$anions (blue) occupying the reconstructed interlayer region.

Phase segregation induced upon thermal treatment was also evaluated by X-ray photoelectron spectroscopy (XPS) and TEM analysis. According to previous reports on the literature [35] Al migrates to inner layers of the structure while collapses and a stable $\mathrm{Mg}(\mathrm{Al}) \mathrm{O}$ mixed oxide is surrounded by more external layers of a MgO-rich layered phase. This assumption was corroborated by the results of XPS analysis summarized in Table 2 with higher $\mathrm{Mg} / \mathrm{Al}$ ratio on CHT than over the commercial unmodified HT. XP spectra corresponding to Au $4 \mathrm{f}$ could not be properly evaluated due to the limited metal loading of the samples and because of the interference of $\mathrm{Mg} 2 \mathrm{~s}$ signal.

Table 2. Surface atomic composition of selected catalysts determined by XPS analysis.

\begin{tabular}{cccccc}
\hline Sample & C 1s & O 1s & Mg 1s & Al 2p & Mg/Al Ratio \\
\hline $\mathrm{Au} / \mathrm{HT}$ & $37.3 \%$ & $32.2 \%$ & $24.5 \%$ & $6.0 \%$ & 4.1 \\
$\mathrm{Au} / \mathrm{CHT}$ & $15.1 \%$ & $30.4 \%$ & $49.7 \%$ & $4.9 \%$ & 10.3 \\
\hline
\end{tabular}

TEM and HAADF-STEM-EDX analysis of the CHT and Au-CHT samples revealed in first place a very good dispersion of the Au NPs (Figure 4a) and that the triangular shape was successfully maintained (Figure $4 b, c$ ). Furthermore, a sort of hierarchically organized core-shell structure containing 
an enriched fraction of Mg in the outer layers was observed by STEM and TEM analysis (Figure 4d,e). Interestingly, the analysis of the chemical composition by EDX rendered an enriched $\mathrm{Mg}$ composition in the outer layers in comparison with the inner areas (Figure $4 \mathrm{~d}-\mathrm{g}$ ). Elemental mappings with sufficient counts could not be properly acquired due to the damage induced by the electron beam probe.
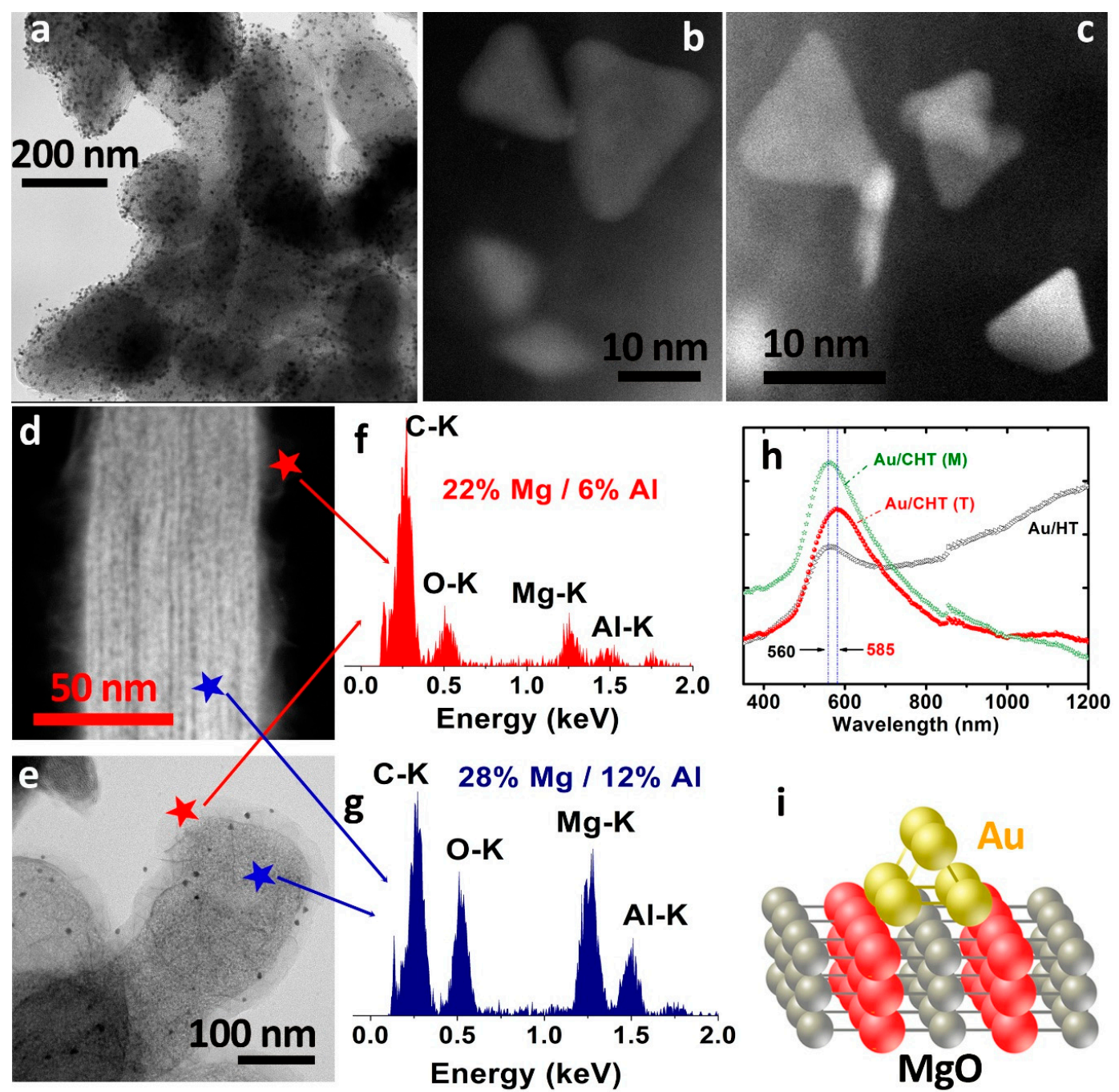

Figure 4. Characterization of the Au-CHT catalysts: (a) Low magnification TEM image of the Au-CHT catalyst; $(\mathbf{b}, \mathbf{c})$ STEM images displaying the triangular-shaped Au NPs preferentially formed onto the CHT supports; (d) STEM-EDX analysis of the reconstructed CHT where two different areas can be distinguished; (e) TEM image clearly discerning the core-shell structure of the CHT support; (f) EDX spectrum corresponding to the outer layer of the CHT (Mg-enriched area); (g) EDX spectrum corresponding to the inner area of the $\mathrm{CHT}$ associated to the partially reconstructed hydrotalcite phase; (h) UV-Vis spectrum comparing the Au-HT (T) catalyst with two other samples prepared with the calcined support (Au-CHT) and where no scattering at higher wavelengths was observed; (i) Scheme of the expected growth model for $\mathrm{Au}$ on $\mathrm{MgO}$ enriched surfaces according to ref. [34].

It is also worth pointing out that the suspension and stability of the Au/CHT catalysts was strongly enhanced in comparison with the $\mathrm{Au} / \mathrm{HT}$ counterparts. This stability was also reflected on the corresponding UV-Vis spectra that show well defined SPR in the Au/CHT samples (Figure 4h) in contrast with the samples deposited on HT that exhibited a broader band extended towards the NIR range associated to absorption events produced by larger nanoparticle agglomerates (see insets in 
Figures 1,2 and $4 \mathrm{~h}$ ). The SPR maximum redshifted to $585 \mathrm{~nm}$ in the sample where more GNT were expected (Figure $4 \mathrm{~h}$ ).

Remarkably, it seems that the HT support plays a key role itself in the in-situ reduction deposition of anisotropic gold nanoparticles. Molina and Hammer [34] proposed a theoretical study where their explanation about the growth mechanism of $\mathrm{Au}$ over $\mathrm{MgO}$ matches with the experimental results described in this work. In their study, the authors established $\mathrm{O}$ sites as the most favourable sites for $\mathrm{Au}$ atoms to deposit. They proposed that $\mathrm{Au}_{3}$ binds in a perpendicular fashion with two $\mathrm{Au}$ atoms on top of two surface $\mathrm{O}$ atoms and the third $\mathrm{Au}$ atom on top of them, favouring the growth of 3D planar assemblies (Figure 4i). In the absence of the support and under the conditions above described, the reduction deposition route led to large round shape Au nanoparticles in first instance, which coalescence and form aggregates overtime $[38,39]$ and in part corroborating the Au nanoparticle stabilization effect of the layered hydroxides (especially the $\mathrm{MgO}$ enriched $\mathrm{CHT}$ ) previously envisioned in bibliography for $\mathrm{MgO}$.

\subsection{Evaluation of Selected Plasmonic Photocatalysts towards the 4-NP Selective Reduction under LED Irradiation}

As previously pointed out (see Figure S1), HT based photocatalyst were not suitable for photocatalytic reactions in water due to their high aggregation that induced low reproducibility in the results. A systematic evaluation of the catalytic response of Au/CHT samples towards the selective reduction of 4-NP into 4-AP (Figure 5a) was carried out given their enhanced colloidal stability in aqueous media in comparison with the Au/HT counterparts. Two catalyst types were selected on the basis of their lower or higher proportion of triangle-shaped Au NPs after being prepared at different $\mathrm{pH}$ conditions. Furthermore and taking into account the plasmonic nature of most of the gold nanostructures decorating the CHT supports, an additional parameter was studied, such as the influence of the irradiation with different LEDs with wavelengths ranging from the UV ( $365 \mathrm{~nm})$, visible (530 and $590 \mathrm{~nm}$ ) and NIR $(850 \mathrm{~nm}$ ) (see Figure $5 \mathrm{~b}-\mathrm{d})$. For the sake of clarity, the conversion of 4-NP has been displayed for all the catalysts and reaction conditions (without and with LED irradiation) at a selected reaction time of $15 \mathrm{~min}$ (see Figure $5 \mathrm{~d}$ and Experimental section for further details). According to the control experiment conditions, in the absence of catalysts (irradiated or not) the concentration of 4-NP remained constant except for the experiments carried out under UV irradiation (see Figure $5 \mathrm{~d}$ ). Therefore, any reaction change could be addressed to the activity of the catalyst or the light irradiation (or a combination of both).

The selective reduction of 4-NP in the presence of Au is usually preceded by an induction time of several minutes. This induction time has been previously attributed to the presence of $\mathrm{O}_{2}$ in the solution. $\mathrm{NaBH}_{4}$ reacts faster with the oxygen in excess than with the 4-NP [22]. The activation time in our experiments, if any, was very short, mainly in the case of the experiments photo-activated with UV irradiation where no activation time could be appreciated, supporting the idea that direct photolysis of the 4-NP is occurring at that specific wavelength. UV irradiation led to the most efficient degradation of the contaminant even in the absence of any catalyst (Figure 5d). This fact can be attributed to the abundant powerful oxidant hydroxyl radical generated by the water base under such irradiation [40] or to direct photolysis of the 4-NP due to the high irradiance of the LEDs used. 4-NP direct photolysis upon irradiation with similar wavelengths has been previously reported. The mechanism was studied using nanosecond flash photolysis exciting with a $355 \mathrm{~nm}$ pulsed laser and it is proposed to take place via the formation of hydroxyl amine by electron transfer to the triplet excited state of the nitrophenol [41]. Significant differences on the degradation rates were especially observed under UV-Vis irradiation. Possible explanations will be discussed further below. 

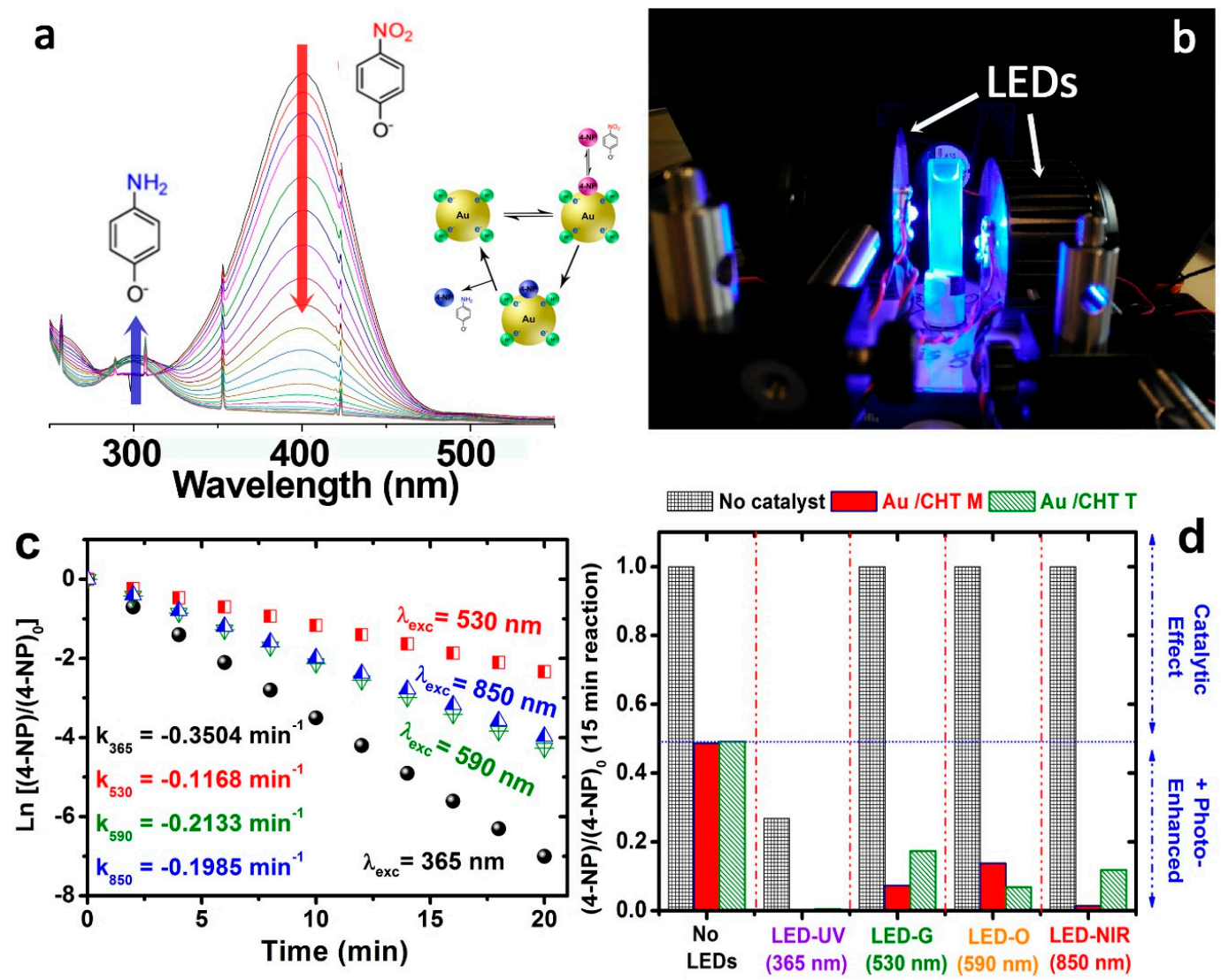

Figure 5. Photocatalytic evaluation of the Au-CHT catalysts: (a) Example of the monitoring of the time-dependent reduction of 4-NP to 4-AP carried out by UV-Vis spectroscopy taking into consideration that 4-Nitrophenolate is detected at $400 \mathrm{~nm}$ and progressive evolve to 4-AP appearing at $300 \mathrm{~nm}$; (b) Digital image corresponding to the experimental setup employed to carry out the photocatalytic experiments; (c) Kinetic rate constant of Au/CHT T experiments $\mathrm{k}\left(\mathrm{min}^{-1}\right)$ after irradiation with different LEDs: $\mathrm{k}_{\text {Non irradiated }}=-0.0451, \mathrm{k}_{365 \mathrm{~nm}}=-0.2035, \mathrm{k}_{530 \mathrm{~nm}}=-0.0651, \mathrm{k}_{590 \mathrm{~nm}}=-0.0598$, $\mathrm{k}_{850 \mathrm{~nm}}=-0.0845$; (d) Comparison of the fraction of 4-NP converted after 15 min of reaction with catalyst Au/CHT T (green dashed bars) and Au/CHT M (red bars) together with the control data without catalyst (black bars) either in the absence of irradiation or after exposure to different LED wavelengths spanning the full-spectrum.

The conventional catalytic reductions (i.e., under no LEDs irradiation) showed good results leading to the complete conversion of the organic pollutant by both $\mathrm{Au} / \mathrm{CHT} \mathrm{M}$ and $\mathrm{Au} / \mathrm{CHT} \mathrm{T}$ although those results were not competitive in terms of kinetic rate constant $\mathrm{k}\left(\mathrm{min}^{-1}\right)$ reported for other Au/HT systems operating in the absence of irradiation sources [42]. However, when irradiated the kinetic rate constant increased sharply, around an order of magnitude, regardless of the LED selected (in the visible-NIR range, see Figure 5c and Figure S3). Especially noteworthy was the increment of the reaction rate under UV irradiation reaching $\mathrm{k}=0.6627 \mathrm{~min}^{-1}$ similar to results obtained by other groups for the catalytic degradation of 4-NP [32].

The differences in the kinetic orders of decomposition under the different irradiation scenarios have been tentatively attributed to two major reasons: (i) the differences on the specific amount of absorbed light by Au nanoparticles to favour a major mobility of absorbed reactants onto its surface and (ii) the different photocatalytic degradation rates of intermediates on the surface of the catalyst due to the effective generation and separation of highly energetic charge carriers [40]. Photocatalytic activity of the support either HT or CHT was discarded due to their elevated band gap energies of 5.06 and $5.4 \mathrm{eV}$, respectively [36]. The experimental results showed a substantial increment in the 
reaction kinetics of 4-NP degradation, not only using UV light but also under Vis and NIR irradiation wavelengths in the presence of the plasmonic photocatalysts, which indicated the effectiveness of this type of catalyst under a wide range of electromagnetic irradiation. Under UV irradiation, 4-NP was also reduced without catalyst. As mentioned before, two different mechanisms could be involved in this reaction. 4-NP could react with hydroxyl radicals generated in the basic aqueous media under UV irradiation, although usually high energy radiation is needed in order to generate those radicals directly from water [40]. Likewise, the potential oxidizing role of the photo-generated holes cannot be completely discarded. In contrast, direct photolysis of 4-NP seems a more plausible option in view of the energy demand claimed in previous works [41]. Hence, the fact that no induction time is observed in the absence of catalyst further reinforces the hypothesis of the direct photo-degradation of 4-NP by UV light.

Figure $5 c$,d shows the kinetics of the experiments carried out with the catalyst Au/CHT T using different irradiation wavelengths. Differences in the kinetic rates between catalyst Au/CHT M and $\mathrm{Au} / \mathrm{CHT} \mathrm{T}$ under visible light irradiation could be attributable to the specific light absorption efficiency for each catalyst (Figure $5 \mathrm{c}$,d) at a certain wavelength being for $\mathrm{Au} / \mathrm{CHT}$ M higher at $850 \mathrm{~nm}$ irradiation (Figure 5d and Figure S3) and lower at $590 \mathrm{~nm}$ respect to the absorbance of the catalyst Au/CHT $\mathrm{T}$. This different behaviour could be attributable to the presence of a higher concentration of small gold triangles in the Au/CHT T catalyst, which will make it more effective under irradiation with wavelengths matching with its plasmon band.

The increment of the kinetic rate constant with Au/CHT T under UV irradiation may be also in part explained by the higher ratio of GNTs present in this catalyst. The geometry of GNT is governed by the preferential appearance of (111) facets which are expected to show negligible activity due to lack of defects in its surface [22]. Thus, catalytic activity must be carried out by the smaller facets (100) corners and (110) triangle thickness or the highly under-coordinated Au sites at the sharp facet's intersections. These corners may form Schottky barriers in the interface with the solid helping to avoid the recombination of carriers generated upon excitation and thus increasing the photocatalytic activity [10,43-45]. The contribution of GNT to the photocatalysts at visible and infrared wavelength may be provided by the concentration of plasmonic near-field enhancement at the triangle corners creating highly energetic hot spots [31,45-47]. Also, UV light has been previously reported to work very well for the degradation of pollutants in gold nanoparticles through an interband transition mechanism [45,48]. Due to the high activity shown by both catalysts at that wavelength, a contribution of interband transitions cannot be ruled out.

\section{Materials and Methods}

\subsection{Chemicals}

All chemicals were used as received, unless otherwise stated. Gold (III) tetrachloroauric acid hydrate $\left(\mathrm{HAuCl}_{4} \cdot 3 \mathrm{H}_{2} \mathrm{O}\right) \geq 99.9 \%$, hydrotalcite $\left(\mathrm{Mg}_{6} \mathrm{Al}_{2}\left(\mathrm{CO}_{3}\right)(\mathrm{OH})_{16} \cdot 4 \mathrm{H}_{2} \mathrm{O}\right)$, 4-nitrophenol $\geq 99.0 \%$, Sodium citrate tribasic dehydrate $\left(\mathrm{HOC}(\mathrm{COONa})\left(\mathrm{CH}_{2} \mathrm{COONa}\right)_{2} 2 \mathrm{H}_{2} \mathrm{O}\right) \geq 99.0 \%$, acetonitrile $(\mathrm{CH} 3 \mathrm{CN})$ $\geq 99.9 \%$ and sodium borohydride $\left(\mathrm{NaBH}_{4}\right) \geq 99.0 \%$ were purchased from Sigma-Aldrich (San Louis, MO, USA).

\subsection{Synthesis of $A u / H T$ and $A u / C H T$ Catalyst: Deposition-Reduction}

Two different supports were used in this work to deposit gold nanoparticles on:

- $\quad$ Commercial Mg/Al HT.

- $\quad \mathrm{Mg}(\mathrm{Al}) \mathrm{O}$ mixed oxide $(\mathrm{CHT})$ obtained after thermal calcination of $\mathrm{HT}$ at $550{ }^{\circ} \mathrm{C}$ (rate: $3{ }^{\circ} \mathrm{C} / \mathrm{min}$ ) for $5 \mathrm{~h}$ in air into a muffle furnace.

The Au/HT catalysts were prepared using a sequential Deposition-Reduction (DR) approach. In first place, HT or CHT (1 g) were dispersed in distilled water $(40 \mathrm{~mL})$ after adjusting the $\mathrm{pH}$ of the 
solution with $\mathrm{Na}(\mathrm{OH}) 0.5 \mathrm{M}$ to reach basic values between 10 and 13 to improve its colloidal stability and mimic the conditions of the catalytic tests. In a typical synthesis, the mixture was stirred for $10 \mathrm{~min}$ until the support was suspended. Afterwards, $3 \mathrm{~mL}$ of solution containing $\mathrm{HAuCl}_{4}(1.2 \mathrm{mM})$ was added dropwise. After stirring for $20 \mathrm{~min}$, the yellow suspension turned white and $2 \mathrm{~mL}$ of sodium citrate solution $\left(1.6 \mathrm{mM}\right.$ ) was added to the mixture. After stirring for $30 \mathrm{~min}$, a fresh $\mathrm{NaBH}_{4}$ (different concentrations from 1 to $11 \mathrm{mM}$ ) solution prepared just before de addition was added. Upon $\mathrm{NaBH}_{4}$ addition the solution turned from light pink to deep bluish purple depending on the different synthesis conditions. The resultant suspension was filtered through a filter paper ( $20 \mu \mathrm{m}$ porous size) under vacuum and washed with warm $\left(60^{\circ} \mathrm{C}\right)$ water and ethanol. The catalysts were dried overnight at $60^{\circ} \mathrm{C}$ in an oven.

\subsection{Characterization Techniques}

The specific surface area of the samples was determined by absorption with a Micromeritics TriStar 3000 V6.08 A (Norcross, GA, USA) at $-196^{\circ} \mathrm{C}$ following degassing at $200{ }^{\circ} \mathrm{C}$. The compositions of the samples were identified by inductively coupled plasma analysis (ICP) using an Agilent 4100 MP-AES (Santa Clara, CA, USA). Samples were first digested with agua regia (1 g catalyst $/ 0.5 \mathrm{~mL}$ agua regia) in a Milestone Ethos Plus (Sorisole, Italy), in which they were heated up to $200{ }^{\circ} \mathrm{C}$ for ten minutes. $X$-ray diffraction patterns for determining the crystal structure of the samples were obtained using an Empyrean, PANalytical diffractometer (Royston, UK), scans were taken with $\mathrm{CuK} \alpha$ radiation at $2 \theta$ intervals of $0.005^{\circ}$ with collection times of $5 \mathrm{~s}$. Ultraviolet visible (UV-VIS) absorption spectra were recorded using a Jasco V-670 UV-VIS-NIR Spectrophotometer (Tokyo, Japan), analysing the catalyst in solid state with an external accessory. The absorption spectra were measured from 300 to $1200 \mathrm{~nm}$. Transmission electron microscopy (TEM) and High-Angle Annular Dark-Field (HAADF-STEM) images were acquired at the Laboratorio de Microscopias Avanzadas (LMA) (Zaragoza, Spain) with the aid of different microscopes (FEI, Tecnai T20, F30, Low-base, Cube models, (Hillsboro, OR, USA) which in some cases included aberration corrector lenses. Samples were suspended in ethanol under ultrasonic treatment and then a drop of the solution was deposited onto a $\mathrm{Cu}$ mesh grid using a pipette and leaving the solvent to evaporate. The particle size distribution was determined by counting $\approx 100$ particles out of the pictures. The geometric aberrations of the probe-forming system were controlled to allow a beam convergence of $24.7 \mathrm{mrad}$ half-angle to be selected. Elemental analysis was carried out with EDS (EDAX) detector which allows performing EDX experiments in scanning mode. The X-ray photoelectron spectroscopy (XPS) analysis was carried out with the aid of XPS Axis Ultra DLD (Kratos Tech., San Diego, CA, USA) equipment and exciting was carried out by the mono-chromatized AlK $\alpha$ source $(1486.6 \mathrm{eV})$ at $15 \mathrm{kV}$ and $10 \mathrm{~mA}$.

\subsection{Photocatalytic Reaction Tests}

Catalytic evaluation in liquid phase: was monitored through UV/Visible spectrophotometry with a Varian Cary ${ }^{\circledR} 50$ UV-Vis Spectrophotometer (Santa Clara, CA, USA). Since 4-NP has a broad absorption band at $317 \mathrm{~nm}$ which overlaps with the formed reaction product (4-aminophenol, 4-AP) at $302 \mathrm{~nm}$, the reaction was monitored by the decrease of the strong peak at $400 \mathrm{~nm}$ which corresponds to the reaction intermediate 4-nitrophenolate anion. The experiments were carried out in alkaline media to displace the 4-NP/nitrophenolate equilibrium and eliminate the activation time of the reaction associated with the 4-NP/4-NP phenolate equilibrium [27]. UV-Vis spectra of initial species can be seen in Figure $4 \mathrm{~d}$. All solutions in the experiment were prepared from a stock $\mathrm{pH} 9.5$ water solution. To a solution of $1.7 \mathrm{~mL}$ 4-Nitrophenol $(\mathrm{C}=0.18 \mathrm{mM})$ and $1 \mathrm{~mL}$ freshly prepared $\mathrm{NaBH}_{4}(\mathrm{C}=15$ $\mathrm{mM})$ a $300 \mu \mathrm{L}$ suspension of $\mathrm{Au} / \mathrm{HT}$ or $\mathrm{Au} / \mathrm{CHT}$ catalyst $(0.05 \mathrm{mM}$ of $\mathrm{Au})$ was added. The reaction mixture was diluted with $3 \mathrm{~mL}$ of water and transferred into a $3 \mathrm{~mL}$ quartz cuvette. The quartz cuvette was then placed inside the spectrophotometer where it remained in the dark along the experiment. The absorption spectra were measured in the range of 250-600 nm. The kinetics of the reduction process was calculated measuring the absorbance of the 4-nitrophenolate ion at $400 \mathrm{~nm}$ as a function 
of time. To study the photocatalytic effect, the same experiment was carried out irradiating the quartz cuvette with two fan-refrigerated Light Emitting Diodes (LEDs). The LEDs illuminated both sides of the cuvette with excitation wavelengths ranging from $365 \mathrm{~nm}$ to $850 \mathrm{~nm}$ and the experimental set up was covered with a black box to assure that the only light reaching the sample came from the selected LEDs (see Figure 5).

\section{Conclusions}

A synthesis of a hybrid photocatalyst composed of gold nanotriangles supported on different hydrotalcites has been successfully developed. The control of the shape and size of the gold nanoparticles has been demonstrated to be strongly dependent on the presence of extremely alkaline conditions and on the use of limited concentrations of reducing agents. The best synthesis scenario has been demonstrated in the presence of thermally modified hydrotalcite supports that evolved to core-shell reconstructed structures with $\mathrm{MgO}$-enriched composition in the outer layers and higher surface areas to ensure a good dispersion of Au NPs. The combination of MgO facets with the deposition-reduction process seems to maximize the successful deployment of triangular-shaped $\mathrm{Au}$ nanostructures and further corroborates previous theoretical calculations. Unlike the Au-HT catalyst with the untreated commercial support, the thermally modified Au-CHT maximized the NP-support interaction, enabled the major percentage of nanotriangles and ensured a proper colloidal stability to perform the catalytic experiments. The plasmonic nature of the gold NPs has enabled the development of a successful set of photocatalysts with enhanced response towards the selective reduction of 4-NP in the full spectrum spanning from UV to NIR wavelengths. Several plasmonic mechanisms can be involved in the high activity showed by the photocatalysts being near field enhancement and interband transition mechanisms the more plausible ones. Precise mechanisms of photocatalysts and photolysis under UV irradiation will need extra investigation.

Supplementary Materials: The following are available online at http:/ /www.mdpi.com/2073-4344/8/9/354/s1, Figure S1: Catalytic tests of the Au-HT system, Figure S2: FTIR spectra of the main catalysts, Figure S3: Kinetic rate constant of $\mathrm{Au} / \mathrm{CHT} \mathrm{M}$ experiments $\mathrm{k}\left(\mathrm{min}^{-1}\right)$ after irradiation with different LEDs.

Author Contributions: Conceptualization, J.L.H. and C.J.B.-A.; Methodology, J.G., J.L.H. and C.J.B.-A.; Validation, J.G., J.L.H. and C.J.B.-A.; Formal Analysis, J.G. and C.J.B.-A.; Investigation, J.G., J.L.H. and C.J.B.-A.; Writing-Original Draft Preparation, C.J.B.-A. and J.L.H.; Writing-Review \& Editing, J.L.H. and C.J.B.-A.; Visualization, J.L.H.

Funding: This research was funded by ARCADIA (grant CTQ2016-77147) and CADENCE (grant 742684) and the APC was waived by the Editorial Team of Catalysts.

Acknowledgments: The TEM measurements were conducted at the Laboratorio de Microscopias Avanzadas, Instituto de Nanociencia de Aragon, Universidad de Zaragoza, Spain. The synthesis of materials was performed by the Platform of Production of Biomaterials and Nanoparticles of the NANOBIOSIS ICTS, more specifically by the Nanoparticle Synthesis Unit of the CIBER in BioEngineering, Biomaterials \& Nanomedicine (CIBER-BBN). The authors also want to acknowledge Silvia Irusta for her aid with the XPS measurements.

Conflicts of Interest: The authors declare no conflict of interest.

\section{References}

1. Benfenati, E.; Facchini, G.; Pierucci, P.; Fanelli, R. Identification of organic contaminants in leachates from industrial waste landfills. TrAC-Trends Anal. Chem. 1996, 15, 305-310. [CrossRef]

2. Dsikowitzky, L.; Botalova, O.; al Sandouk-Lincke, N.A.; Schwarzbauer, J. Identification of specific organic contaminants in different units of a chemical production site. Environ. Sci-Process. Impacts 2014, 16, 1779-1789. [CrossRef] [PubMed]

3. Bokare, A.D.; Choi, W.Y. Chromate-induced activation of hydrogen peroxide for oxidative degradation of aqueous organic pollutants. Environ. Sci. Technol. 2010, 44, 7232-7237. [CrossRef] [PubMed]

4. Grisel, R.; Weststrate, K.J.; Gluhoi, A.; Nieuwenhuys, B.E. Catalysis by gold nanoparticles. Gold Bull. 2002, 35, 39-45. [CrossRef] 
5. Sun, Y.G.; Xia, Y.N. Shape-controlled synthesis of gold and silver nanoparticles. Science 2002, 298, $2176-2179$. [CrossRef] [PubMed]

6. Ortega-Liebana, M.C.; Hueso, J.L.; Ferdousi, S.; Arenal, R.; Irusta, S.; Yeung, K.L.; Santamaria, J. Extraordinary sensitizing effect of co-doped carbon nanodots derived from mate herb: Application to enhanced photocatalytic degradation of chlorinated wastewater compounds under visible light. Appl. Catal. B-Environ. 2017, 218, 68-79. [CrossRef]

7. Xu, Z.H.; Liu, Y.L.; Ren, F.Q.; Yang, F.; Ma, D.L. Development of functional nanostructures and their applications in catalysis and solar cells. Coord. Chem. Rev. 2016, 320, 153-180. [CrossRef]

8. Wojcieszak, R.; Ferraz, C.P.; Sha, J.; Houda, S.; Rossi, L.M.; Paul, S. Advances in base-free oxidation of bio-based compounds on supported gold catalysts. Catalysts 2017, 7, 23. [CrossRef]

9. Gómez, L.; Hueso, J.L.; Ortega-Liébana, M.C.; Santamaría, J.; Cronin, S.B. Evaluation of gold-decorated halloysite nanotubes as plasmonic photocatalysts. Catal. Commun. 2014, 56, 115-118. [CrossRef]

10. Ortega-Liebana, M.C.; Hueso, J.L.; Arenal, R.; Santamaria, J. Titania-coated gold nanorods with expanded photocatalytic response. Enzyme-like glucose oxidation under near-infrared illumination. Nanoscale 2017, 9, 1787-1792. [CrossRef] [PubMed]

11. Zieba, M.; Hueso, J.L.; Arruebo, M.; Martínez, G.; Santamaría, J. Gold-coated halloysite nanotubes as tunable plasmonic platforms. New J. Chem. 2014, 38, 2037-2042. [CrossRef]

12. Costa, F.R.; Leuteritz, A.; Wagenknecht, U.; Jehnichen, D.; Haussler, L.; Heinrich, G. Intercalation of mg-al layered double hydroxide by anionic surfactants: Preparation and characterization. Appl. Clay Sci. 2008, 38, 153-164. [CrossRef]

13. Hallett-Tapley, G.L.; Silvero, M.J.; Bueno-Alejo, C.J.; Gonzalez-Bejar, M.; McTiernan, C.D.; Grenier, M.; Netto-Ferreira, J.C.; Scaiano, J.C. Supported gold nanoparticles as efficient catalysts in the solvent less plasmon mediated oxidation of sec-phenethyl and benzyl alcohol. J. Phys. Chem. C 2013, 117, 12279-12288. [CrossRef]

14. Arcanjo, G.S.; Mounteer, A.H.; Bellato, C.R.; da Silva, L.M.M.; Dias, S.H.B.; da Silva, P.R. Heterogeneous photocatalysis using tio2 modified with hydrotalcite and iron oxide under uv-visible irradiation for color and toxicity reduction in secondary textile mill effluent. J. Environ. Manag. 2018, 211, 154-163. [CrossRef] [PubMed]

15. Xiao, Q.; Liu, Z.; Wang, F.; Sarina, S.; Zhu, H.Y. Tuning the reduction power of visible-light photocatalysts of gold nanoparticles for selective reduction of nitroaromatics to azoxy-compounds-tailoring the catalyst support. Appl. Catal. B-Environ. 2017, 209, 69-79. [CrossRef]

16. Xiao, G.F.; Zeng, H.Y.; Xu, S.; Chen, C.R.; Zhao, Q.; Liu, X.J. Preparation of ti species coating hydrotalcite by chemical vapor deposition for photodegradation of azo dye. J. Environ. Sci. 2017, 60, 14-23. [CrossRef] [PubMed]

17. Mantilla, A.; Jacome-Acatitla, G.; Morales-Mendoza, G.; Tzompantzi, F.; Gomez, R. Photoassisted degradation of 4-chlorophenol and p-cresol using mgal hydrotalcites. Ind. Eng. Chem. Res. 2011, 50, 2762-2767. [CrossRef]

18. Debek, R.; Motak, M.; Grzybek, T.; Galvez, M.E.; Da Costa, P. A short review on the catalytic activity of hydrotalcite-derived materials for dry reforming of methane. Catalysts 2017, 7, 25. [CrossRef]

19. Guo, D.P.; Wang, Y.; Zhao, P.; Bai, M.F.; Xin, H.; Guo, Z.; Li, J.Y. Selective aerobic oxidation of benzyl alcohol driven by visible light on gold nanoparticles supported on hydrotalcite modified by nickel ion. Catalysts 2016, 6, 13. [CrossRef]

20. Pirkanniemi, K.; Sillanpaa, M. Heterogeneous water phase catalysis as an environmental application: A review. Chemosphere 2002, 48, 1047-1060. [CrossRef]

21. Herrmann, J.M. Heterogeneous photocatalysis: Fundamentals and applications to the removal of various types of aqueous pollutants. Catal. Today 1999, 53, 115-129. [CrossRef]

22. Hajfathalian, M.; Gilroy, K.D.; Yaghoubzade, A.; Sundar, A.; Tan, T.; Hughes, R.A.; Neretina, S. Photocatalytic enhancements to the reduction of 4-nitrophenol by resonantly excited triangular gold-copper nanostructures. J. Phys. Chem. C 2015, 119, 17308-17315. [CrossRef]

23. Schaadt, D.M.; Feng, B.; Yu, E.T. Enhanced semiconductor optical absorption via surface plasmon excitation in metal nanoparticles. Appl. Phys. Lett. 2005, 86, 3. [CrossRef]

24. Hewitt, M.; Servos, M. An overview of substances present in canadian aquatic environments associated with endocrine disruption. Water Qual. Res. J. Can. 2001, 36, 191-213. [CrossRef] 
25. Larous, S.; Meniai, A.H. Elimination of organic pollutants from wastewater. Application to p-nitrophenol. Desal. Water Treat. 2013, 51, 5014-5020. [CrossRef]

26. Li, M.L.; Chen, G.F. Revisiting catalytic model reaction p-nitrophenol/nabh4 using metallic nanoparticles coated on polymeric spheres. Nanoscale 2013, 5, 11919-11927. [CrossRef] [PubMed]

27. Zhao, P.X.; Feng, X.W.; Huang, D.S.; Yang, G.Y.; Astruc, D. Basic concepts and recent advances in nitrophenol reduction by gold- and other transition metal nanoparticles. Coord. Chem. Rev. 2015, 287, 114-136. [CrossRef]

28. Kuroda, K.; Ishida, T.; Haruta, M. Reduction of 4-nitrophenol to 4-aminophenol over au nanoparticles deposited on pmma. J. Mol. Catal. A-Chem. 2009, 298, 7-11. [CrossRef]

29. Li, Y.H.; Geng, X.; Leng, W.N.; Vikesland, P.J.; Grove, T.Z. Gold nanospheres and gold nanostars immobilized onto thiolated eggshell membranes as highly robust and recyclable catalysts. New J. Chem. 2017, 41, 9406-9413. [CrossRef]

30. Liu, Y.; Xu, L.; Liu, X.Y.; Cao, M.N. Hybrids of gold nanoparticles with core-shell hyperbranched polymers: Synthesis, characterization, and their high catalytic activity for reduction of 4-nitrophenol. Catalysts 2016, 6, 14. [CrossRef]

31. Chen, L.; Ji, F.; Xu, Y.; He, L.; Mi, Y.F.; Bao, F.; Sun, B.Q.; Zhang, X.H.; Zhang, Q. High-yield seedless synthesis of triangular gold nanoplates through oxidative etching. Nano Lett. 2014, 14, 7201-7206. [CrossRef] [PubMed]

32. Hallett-Tapley, G.L.; Crites, C.O.L.; Gonzalez-Bejar, M.; McGilvray, K.L.; Netto-Ferreira, J.C.; Scaiano, J.C. Dry photochemical synthesis of hydrotalcite, gamma- $\mathrm{Al}_{2} \mathrm{O}_{3}$ and $\mathrm{TiO}_{2}$ supported gold nanoparticle catalysts. J. Photochem. Photobiol. A-Chem. 2011, 224, 8-15. [CrossRef]

33. Uson, L.; Sebastian, V.; Mayoral, A.; Hueso, J.L.; Eguizabal, A.; Arruebo, M.; Santamaria, J. Spontaneous formation of au-pt alloyed nanoparticles using pure nano-counterparts as starters: A ligand and size dependent process. Nanoscale 2015, 7, 10152-10161. [CrossRef] [PubMed]

34. Molina, L.M.; Hammer, B. Theoretical study of co oxidation on au nanoparticles supported by mgo(100). Phys. Rev. B 2004, 69, 22. [CrossRef]

35. Roelofs, J.; van Bokhoven, J.A.; van Dillen, A.J.; Geus, J.W.; de Jong, K.P. The thermal decomposition of mg-al hydrotalcites: Effects of interlayer anions and characteristics of the final structure. Chem.-A Eur. J. 2002, 8, 5571-5579. [CrossRef]

36. Stanimirova, T.; Piperov, N.; Petrova, N.; Kirov, G. Thermal evolution of Mg-Al-CO 3 hydrotalcites. Clay Miner. 2004, 39, 177-191. [CrossRef]

37. Rey, F.; Fornes, V.; Rojo, J.M. Thermal-decomposition of hydrotalcites-An infrared and nuclear-magnetic-resonance spectroscopic study. J. Chem. Soc.-Faraday Trans. 1992, 88, 2233-2238. [CrossRef]

38. Deraedt, C.; Salmon, L.; Gatard, S.; Ciganda, R.; Hernandez, R.; Ruiz, J.; Astruc, D. Sodium borohydride stabilizes very active gold nanoparticle catalysts. Chem. Commun. 2014, 50, 14194-14196. [CrossRef] [PubMed]

39. Zhang, Z.Q.; Wu, Y.H. Investigation of the $\mathrm{NaBH}_{4}$-induced aggregation of au nanoparticles. Langmuir 2010, 26, 9214-9223. [CrossRef] [PubMed]

40. Han, W.Y.; Zhu, W.P.; Zhang, P.Y.; Zhang, Y.; Li, L.S. Photocatalytic degradation of phenols in aqueous solution under irradiation of 254 and $185 \mathrm{~nm}$ uv light. Catal. Today 2004, 90, 319-324. [CrossRef]

41. Barsotti, F.; Bartels-Rausch, T.; De Laurentiis, E.; Arnmann, M.; Brigante, M.; Mailhot, G.; Maurino, V.; Minero, C.; Vione, D. Photochemical formation of nitrite and nitrous acid (hono) upon irradiation of nitrophenols in aqueous solution and in viscous secondary organic aerosol proxy. Environ. Sci. Technol. 2017, 51, 7486-7495. [CrossRef] [PubMed]

42. Holden, M.S.; Nick, K.E.; Hall, M.; Milligan, J.R.; Chen, Q.; Perry, C.C. Synthesis and catalytic activity of pluronic stabilized silver-gold bimetallic nanoparticles. RSC Adv. 2014, 4, 52279-52288. [CrossRef] [PubMed]

43. Matamoros-Ambrocio, M.; Ruiz-Peralta, M.D.; Chigo-Anota, E.; Garcia-Serrano, J.; Perez-Centeno, A.; Sanchez-Cantu, M.; Rubio-Rosas, E.; Escobedo-Morales, A. A comparative study of gold impregnation methods for obtaining metal/semiconductor nanophotocatalysts: Direct turkevich, inverse turkevich, and progressive heating methods. Catalysts 2018, 8, 161. [CrossRef]

44. Sa, J.; Tagliabue, G.; Friedli, P.; Szlachetko, J.; Rittmann-Frank, M.H.; Santomauro, F.G.; Milne, C.J.; Sigg, H. Direct observation of charge separation on au localized surface plasmons. Energy Environ. Sci. 2013, 6, 3584-3588. [CrossRef] 
45. Sarina, S.; Waclawik, E.R.; Zhu, H.Y. Photocatalysis on supported gold and silver nanoparticles under ultraviolet and visible light irradiation. Green Chem. 2013, 15, 1814-1833. [CrossRef]

46. Fasciani, C.; Alejo, C.J.B.; Grenier, M.; Netto-Ferreira, J.C.; Scaiano, J.C. High-temperature organic reactions at room temperature using plasmon excitation: Decomposition of dicumyl peroxide. Org. Lett. 2011, 13, 204-207. [CrossRef] [PubMed]

47. Kuttner, C.; Mayer, M.; Dulle, M.; Moscoso, A.; Lopez-Romero, J.M.; Forster, S.; Fery, A.; Perez-Juste, J.; Contreras-Caceres, R. Seeded growth synthesis of gold nanotriangles: Size control, saxs analysis, and sers performance. ACS Appl. Mater. Interfaces 2018, 10, 11152-11163. [CrossRef] [PubMed]

48. Zhu, H.Y.; Chen, X.; Zheng, Z.F.; Ke, X.B.; Jaatinen, E.; Zhao, J.C.; Guo, C.; Xie, T.F.; Wang, D.J. Mechanism of supported gold nanoparticles as photocatalysts under ultraviolet and visible light irradiation. Chem. Commun. 2009, 7524-7526. [CrossRef] [PubMed]

(C) 2018 by the authors. Licensee MDPI, Basel, Switzerland. This article is an open access article distributed under the terms and conditions of the Creative Commons Attribution (CC BY) license (http://creativecommons.org/licenses/by/4.0/). 